the perfusate and demonstrated that these antigenic components originated from the serum and that the duct perfusate did not contain any of the intrinsic submaxillary gland antigens. The presence of serum antigens was confirmed by studying the perfusate with antiserum to rat serum. Immunoelectrophoretic studies demonstrated the presence of both serum albumin and globulins in addition to other serum constituents (fig.). Measurements of total protein of perfusate averaged $1.8 \mathrm{~g} / 100$ $\mathrm{ml} \pm 0.4$ ( \pm SE obtained from nine animals). Neither total protein concentration nor the immunoelectrophoretic pattern of the perfusate was significantly altered by isoproterenol administration.

Discussion. The presence of serum proteins in saliva is well documented $^{10}$, but the mechanism of secretion of these components is not understood. However, since isoproterenol had no effect on the passage of the serum proteins through the duct epithelium, it may be concluded from the present data that there

1 Acknowledgments. This work was supported by orant DE 02110 from the National Institute of Dental Research, Bethesda, Maryland 20205 , USA. This work was performed in the laboratory of Leon $\mathrm{H}$. Schneyer at his suggestion.

2 Martinez, J. R., Holzgreve, H., and Frick, A., Arch. ges. Physiol. 290 (1966) 124.

3 Young, J.A., Fromter, E., Schogel, E., and Hamann, K. F., Arch. ges. Physiol. 215 (1967) 157.

4 Young, J.A., Martin, C.J., Asz, M., and Weber, F.D., Arch. ges Physiol. 319 (1970) 185.

5 Schneyer, L. H., Am. J. Physiol. 215 (1968) 664

6 El-Mofty, S., Experientia 30 (1974) 301.

7 Lowry, O.H., Rosebrough, N. J., Farr, A. L., and Randall, R. J., J. biol. Chem. 193 (1951) 265. is no $\beta$-adrenergic control of this event. In fact, from previous work it appears likely that the passage of these serum proteins is not influenced by stimulation of any autonomic receptors. In previous studies on the whole parotid gland it has been noted that the ratio of albumin and IgG in saliva was about the same as that in serum ${ }^{11}$ and that the secretion of these molecules was independent of flow rate and kind of stimulation ${ }^{12,13}$. The present study shows the specific function of the ductal epithelium of the submaxillary gland in the transport of serum proteins. These data demonstrate the passive transport of serum proteins from serum and shows that the duct plays an important role in the transfer of organic as well as inorganic components. The observed absence of intrinsic submaxillary gland antigens in the perfusate shows that the excretory submaxillary duct of the rat does not participate in the secretion of these antigens and demonstrates the absence of salivary contamination in our samples.

8 Grabar, P., and Burtin, P., Analyse Immuno-Electrophorétique. Masson and Cie, Paris 1960.

9 Scheideggar, J. J., Int. Archs Allergy 7 (1955) 103

10 Ellison, S. A., in: Handbook of Physiology, vol.2, p. 531. Ed. C. F. Code. Williams and Wilkins, Baltimore 1967.

11 El-Mofty, S., IADR 52 (1974) 511.

12 El-Mofty, S.. IADR 51 (1973) 679.

13 El-Mofty, S., and Schneyer, C.A., Proc. Soc. exp. Biol. Med. 158 (1978) 59 .

$0014-4754 / 85 / 121548-02 \$ 1.50+0.20 / 0$

(C) Birkhäuser Verlag Basel, 1985

\title{
Isolation and characterization of a high-molecular-weight glycoprotein from the endometrium of porcine uteri
}

\author{
H. Munakata, M. Isemura, J. Aikawa and Z. Yosizawa \\ Department of Biochemistry, Tohoku University School of Medicine, Sendai 980 (Japan), 17 December 1984
}

Summary. A novel glycoprotein was isolated from the endometrium of porcine uteri. This high-molecular-weight glycoprotein consisted of $25 \%$ of protein and $73 \%$ of carbohydrate. The carbohydrate composition was quite characteristic in that equimolar $\mathrm{N}$-acetylglucosamine and galactose were major constituents. Its unique nature makes it distinguishable from hitherto-reported glycoproteins.

Key words. Neutral glycoprotein; porcine uteri.

We are interested in the glycoproteins of uterine endometrium', since implantation may possibly be mediated by interaction between the cell surface of a fertilized egg and the glycoconjugates of the cells or matrices in the endometrium. During the course of studies on glycoproteins from porcine uteri, we have found a hitherto undescribed glycoprotein with a high molecular weight. This paper reports its isolation and partial characterization. Materials and methods. Porcine uteri were obtained from a local slaughter house. The uteri, freed from adhering tissues, were opened by longitudinal cutting and rinsed with ice-cold $0.9 \%$ $\mathrm{NaCl}$. All operations were carried out at $4^{\circ} \mathrm{C}$ unless otherwise stated. The endometrium was scraped off from the uteri, weighed and homogenized in 100 volumes of $5 \mathrm{mM}$ EDTA (the $\mathrm{pH}$ of the solution was adjusted to 7.0 with $1 \mathrm{~N} \mathrm{NaOH}$ ) with a Waring blender. The homogenate was centrifuged at $20,000 \mathrm{rpm}$ for $2 \mathrm{~h}$. Concentrated potassium phosphate buffer was added to the supernatant $(\mathrm{pH} 7.0)$ to make the solution $50 \mathrm{mM}$. The solution was applied to a column $(4 \times 22 \mathrm{~cm})$ of DEAE-Sephadex A-25 pre-equilibrated with $50 \mathrm{mM}$ potassium phosphate (pH 7.0), and the column was washed with the same buffer. The eluate and the washing buffer were combined and applied to a column $(2.5 \times 30 \mathrm{~cm})$ of CM-Sephadex $\mathrm{C}-25$ pre-equilibrated with the same buffer. The column was washed with the same buffer. The eluates and the washings were combined, concentrated to a small volume by ultrafiltration and applied to a column of Sepharose CL-4B pre-equilibrated with the same buffer. The fractions eluted at the void volume were combined, dialyzed and lyophilized

Electrophoresis on cellulose acetate membranes ${ }^{2}$, sodium dodecylsulfate- $1 \%$ agarose gels ${ }^{3}$ and sodium dodecylsulfate- $3.3 \%$ polyacrylamide gels ${ }^{3}$ were carried out as described previously. Hexoses $^{4}$, hexosamines ${ }^{5}$, sialic acid $^{5}$ and amino acids ${ }^{5}$ were quantitated according to the methods described previously.

Amino acid composition of the glycoprotein. The data are expressed as residues per 1000 residues

\begin{tabular}{lrlr}
\hline Aspartic acid & 69 & Methionine & 3 \\
Threonine & 55 & Isoleucine & 32 \\
Serine & 109 & Leucine & 62 \\
Glutamic acid & 128 & Tyrosine & 24 \\
Proline & 61 & Phenylalanine & 30 \\
Glycine & 158 & Lysine & 48 \\
Alanine & 58 & Histidine & 20 \\
Valine & 77 & Arginine & 51 \\
Half cystine & 5 & Tryptophan & 10 \\
\hline
\end{tabular}


Results and discussion. In a typical experiment, $20 \mathrm{~g}$ of the porcine endometrium yielded about $1 \mathrm{~g}$ of $5 \mathrm{mM}$ EDTA soluble material. The solubilized material was subjected to anion and cation exchange chromatography and the pass-through fraction was then fractionated by gel-filtration through Sepharose CL4B (fig. 1). The void volume fraction yielded a glycoprotein ( 8 $\mathrm{mg}$ ). Sodium dodecylsulfate-agarose gel electrophoresis revealed that the glycoprotein gave a single slow-migrating band stainable by the periodic acid-Schiff reaction (fig. 2a). Reduction with 2-mercaptoethanol resulted in no change in mobility, suggesting that there were no intermolecular disulfide bridges. On cellulose acetate membrane electrophoresis the present glycoprotein migrated as a single band stainable by the periodic acid-Schiff reaction. The mobility was comparable with that of glycogen, indicating electrostatical neutrality of this glycoprotein. The glycoprotein did not penetrate into $3.3 \%$ polyacrylamide gel and no bands were detected by staining with Coomassie brilliant blue (fig. 2c).

The glycoprotein was subjected to gel-filtration on a column $(1.2 \times 140 \mathrm{~cm})$ of Sepharose CL-2B pre-equilibrated with 10 $\mathrm{mM}$ potassium phosphate/150 $\mathrm{mM} \mathrm{NaCl}(\mathrm{pH} \mathrm{7.0)}$. The Kav value was determined by referring to Escherichia coli (for the void volume) and phenol red (for the total volume), and compared with that of dextran with an average molecular weight of $2,000,000$ (Sigma). The Kav value (0.05) of the glycoprotein thus obtained was much lower than that $(0.74)$ of dextran, indicating the very large molecular size of this glycoprotein $(>2,000,000)$. The carbohydrate analysis indicated that the glycoprotein contained galactose $(26.6 \%$ by weight), mannose $(2.1 \%)$, glucose $(2.1 \%), \mathrm{N}$-acetylglucosamine $(39.4 \%)$ and $\mathrm{N}$-acetylgalactosamine $(2.3 \%)$. Neither sialic acid nor fucose was detected. Thus the glycoprotein contained $\mathrm{N}$-acetylglucosamine and galactose as the major carbohydrate constituents. The amino acid analysis indicated that a protein portion represented $24.8 \%$ by weight of the glycoprotein and that glycine, glutamic acid and serine were the predominant amino acids, as shown in the table. The carbohydrate composition of the present glycoprotein was quite characteristic in that it contained equimolar $\mathrm{N}$-acetylglucosamine and galactose as the major constituents. Keratan sulfate $^{6}$ and polylactosaminoglycan ${ }^{7}$ have been known to have such a composition. The present glycoprotein, however, is distinct from keratan sulfate because the former is neutral at either $\mathrm{pH} 3.0$ or $\mathrm{pH}$ 8.6. The present glycoprotein is also distinguishable from the polylactosaminoglycan, since the latter is negative toward the periodic acid-Schiff reaction. A preliminary experiment has also shown that the present glycoprotein is not sensitive to Escherichia freundii endo- $\beta$-galactosidase, unlike the polylactosaminoglycans. As for uterine glycoproteins, uteroglobin $^{8}$, sulfated glycoprotein ${ }^{1}$, and lavender protein ${ }^{9}$ have been reported.

The lavender protein is basic and has a mol. wt of about 32,000 . These characteristics differ from those of the present glycoprotein. Thus the glycoprotein isolated here can be distinguished from any of the known glycoproteins from uterine and other tissues by its high molecular weight nature, unique chemical composition and electrostatic neutrality.

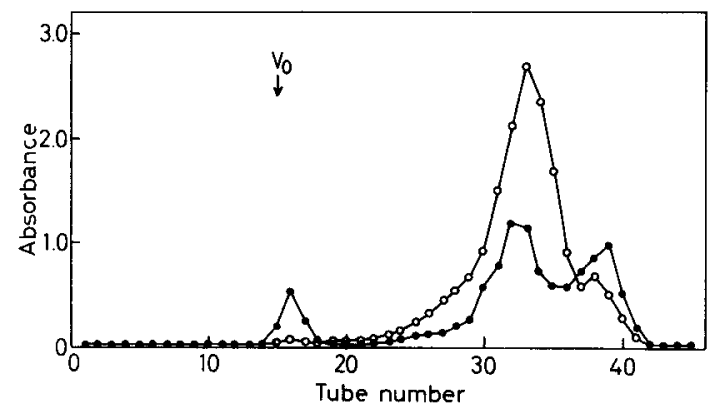

Figure 1. Separation of a high-molecular-weight glycoprotein by gel-filtration through Sepharose CL-4B. The sample was applied onto a column $(2.5 \times 90 \mathrm{~cm})$ of Sepharose CL-4B pre-equilibrated with $50 \mathrm{mM}$ potassium phosphate buffer ( $\mathrm{pH} 7.0$ ). Elution was carried out with the same buffer. Fractions of $10 \mathrm{ml}$ were collected and monitored for protein at 280 $\mathrm{nm}(\mathrm{O}-\mathrm{O})$ and for sugars at $490 \mathrm{~nm}(-)$ in the phenol- $\mathrm{H}_{2} \mathrm{SO}_{4}$ reaction. $V_{0}$, void volume.
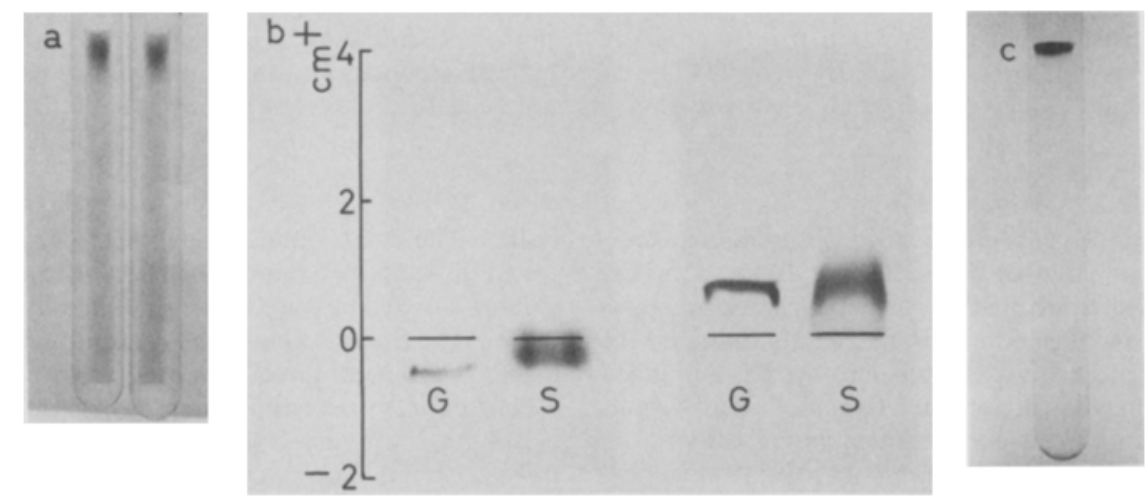

Figure 2. Electrophoretograms of the glycoprotein. $a$ The glycoprotein was analyzed by sodium dodecylsulfate-1\% agarose gel electrophoresis before (left) and after (right) reduction with 2-mercaptoethanol. $b$ Cellulose acetate membrane electrophoresis was performed in veronal buffer (pH 8.6) (left) and in pyridine-formate buffer (pH 3.0) (right) at $1 \mathrm{~mA} / \mathrm{cm}$ for $25 \mathrm{~min}$. The glycoprotein (S) and glycogen (G) were visualized by the periodic acid-Schiff reaction. $c$ Sodium dodecylsulfate-3.3\% polyacrylamide gel electrophoresis. The gel was stained by the periodic acid-Schiff reaction.

1 Endo, M., and Yosizawa, Z., J. Biochem., Tokyo 78 (1975) 873

2 Munakata, H., and Yosizawa, Z., J. Biochem., Tokyo 84 (1978) 1587.

3 Munakata, H., and Yosizawa, Z., J. Biochem., Tokyo 87 (1980) 1559.

4 Munakata, H., Schmid, K., Collins, J. H., Zot, A. S., Lane, L. K., and Schwartz, A., Biochem. biophys. Res. Comm. 107 (1982) 229.

5 Munakata, H., and Yosizawa, Z., Biochim. biophys. Acta 623 (1980) 412.

6 Rodén, L., Baker, J.R., Cifonelli, J.A., and Mathews, M. B., in: Methods in Enzymology, vol.28, p. 73. Ed. V. Ginsberg. Academic Press, New York 1972
7 Krusius, T., Finne, J., and Rauvala, H., Eur. J. Biochem. 92 (1978) 298.

8 Beier, H.N., Biochim. biophys. Acta 160 (1968) 289.

9 Chen, T. T., Bazer, F. W., Cetorelli, J. J., Pollard, W. E., and Roberts, R. M., J. biol. Chem. 248 (1973) 8560 .

$0014-4754 / 85 / 121549-02 \$ 1.50+0.20 / 0$

(C) Birkhäuser Verlag Basel, 1985 